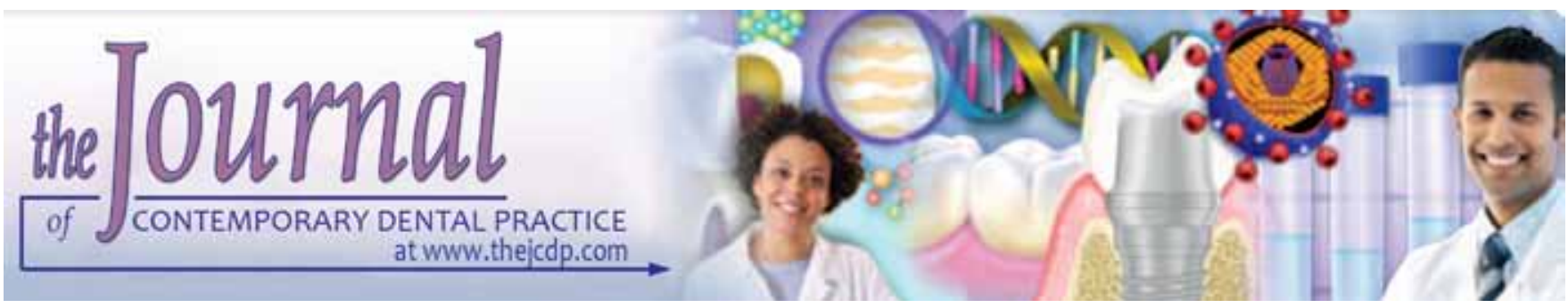

\title{
In vivo Evaluation of Proximal Resin Composite Restorations performed using Three Different Matrix Systems
}

\footnotetext{
${ }^{1}$ Isabella Azevedo Gomes, ${ }^{2}$ Etevaldo Matos Maia Filho, ${ }^{3}$ Debora Castelo Branco Rios Mariz, ${ }^{4}$ Alvaro Henrique Borges

${ }^{5}$ Mateus Rodrigues Tonetto, ${ }^{6}$ Leily Macedo Firoozmand, ${ }^{7}$ Carlos Milton Kuga, ${ }^{8}$ Rudys Rodolfo De Jesus Tavarez

${ }^{9}$ Matheus Coelho Bandéca
}

\begin{abstract}
Objective: The aim of this in vivo study was to radiographically evaluate the proximal contour of composite resin restorations performed using different matrix systems.

Materials and methods: Patients with premolars needing class II type resin composite restorations involving the marginal ridge were selected. Thirty premolars were selected and randomly divided into three groups ( $n=10$ each) to receive restorations using different matrix systems: group 1: metal matrix coupled to a carrier matrix and wood wedge (G1-MMW); group 2: sectioned and precontoured metal matrix and elastic wedge (G2-SME); and group 3: a polyester strip and reflective wedge (G3-PMR). After the restorative procedure, bitewing radiographs were performed and analyzed by three calibrated professionals. The quality of the proximal contact and marginal adaptation of the proximal surfaces was classified as either correct or incorrect (undercontour/overcontour).
\end{abstract}

Results: The Pearson Chi-square statistical test ( $\alpha=5 \%$ ) revealed a statistically difference between frequencies of correct and incorrect restorations $\left(\alpha^{2}=6.787, p<0.05\right)$. The group $G 2$ SME produced a higher frequency of correct proximal contours $(90 \%)$, while G1-MMW and G3-PMR had a ratio of $40 \%$ correct and $60 \%$ incorrect contours respectively.

\footnotetext{
1-3,8,9 Department of Postgraduate in Dentistry, CEUMA University, São Luis, MA, Brazil

${ }^{4,5}$ Department of Postgraduate in Integrated Dental Science University of Cuiaba, Cuiaba, MT, Brazil

${ }^{6}$ Department of Dentistry I, Federal University of MaranhãoUFMA, São Luis, MA, Brazil

${ }^{7}$ Department of Restorative Dentistry, Araraquara Dental School, Univ Estadual Paulista, Araraquara, São Paulo, Brazil

Corresponding Author: Matheus Coelho Bandéca, Professor Department of Postgraduate in Dentistry, CEUMA University Rua Jossue Montello, 01, São Luis, MA, Brazil, e-mail: mbandeca@gmail.com
}

Conclusion: None of the matrix systems was able to prevent the formation of incorrect proximal contours; however, the sectioned and precontoured metal matrix/elastic wedge configuration provided better results as compared to the other groups.

Keywords: Composite resins, Esthetics, Radiography.

How to cite this article: Gomes IA, Filho EMM, Mariz DCBR, Borges AH, Tonetto MR, Firoozmand LM, Kuga CM, De Jesus $\mathrm{RRT}$, Bandéca MC. In vivo Evaluation of Proximal Resin Composite Restorations performed using Three Different Matrix Systems. J Contemp Dent Pract 2015;16(8):643-647.

Source of support: Nil

Conflict of interest: None

\section{INTRODUCTION}

Composite resin has gained great prominence as a result of advances in esthetic restorative materials. Increased esthetic requirements and improved mechanical properties have led resin composite restorations to become routine in clinical practice. ${ }^{1}$

In recent years, there has been an increase in the indi cation and use of composite resins for posterior teeth by various dental schools. ${ }^{2-4}$ Currently, professionals are gaining experience regarding replacing amalgam with composite resin. However, the performance of resin composite restorations in posterior teeth still represents a major clinical challenge for the professionals. ${ }^{2}$

One of the challenges encountered when performing direct restoration involving the proximal walls is the adequate restoration of the proximal contour and contact. Thus, several studies have analyzed techniques and materials capable of re-establishing the correct proximal contact tightness. ${ }^{5-8}$ In this regard, the type of technique adopted is known to affect the quality of the proximal. ${ }^{6,9}$ 
An adequate proximal contact tightness and contour is of utmost importance in balancing the dental element, and thus, in periodontal health. ${ }^{10,11}$ Contact with the adjacent tooth must allow sufficient occlusal force to be exerted during chewing to maintain the integrity of the dental arch. ${ }^{12}$

Performing adhesive and esthetic restorations in proximal cavities in posterior teeth require a sequence of clinical steps. In these cases, it is important to develop techniques and materials that minimize polymerization shrinkage, as this shrinkage is responsible for the appearance of microleakage and the consequent failure of the restoration. ${ }^{13}$ Additionally, the difficulty of achieving adequate proximal contours, with tight proximal contact and proper marginal adaptation, sometimes requires special techniques and surgical instruments. ${ }^{14}$

The use of medium- and high-viscosity composite resins results in a more precise and adequate proximal contact than using low-viscosity resins. ${ }^{15}$ However, studies have demonstrated that high-viscosity 'compactable' resins do not necessarily guarantee better proximal contact, and that the matrix system used may exert a more significant effect than the consistency of the composite resin. ${ }^{15,16}$

Restorative dental materials and devices for simplifying clinical work are constantly being developed, and it is necessary to conduct studies to evaluate the effectiveness of these systems. Thus, the aim of the present in vivo study was to use radiographic evaluation to verify the quality of the proximal contour established after completing class II restorations, with microhybrid composite resin using three matrix devices. The null hypothesis was that there would be no significant difference between the matrix devices studied.

\section{MATERIALS AND METHODS}

This study was approved by the Research Ethics Committee of the São Leopoldo Mandic/Dental School under protocol number 2011/0049, and conducted in the Restorative Dentistry clinic of the Dental School of CEUMA University, São Luis, MA, Brazil.

The calculation of the sample was performed taking into consideration the usage of three groups, an effect size of 0.5 , an alpha value of 0.5 , and a power of testing for analysis of the Chi-square of 0.7 with $2^{\circ}$ of freedom. The result was 30 teeth, or 10 per group (PASS 11, NCSS, LLC, Kaysville, Utah, USA, www.ncss.com).

The radiographic and restorative procedures were performed after an appointment with and request for a dentist, and after the patient agreed to participate by signing a consent form.
The inclusion criteria for the study were patients with 1st and 2nd upper premolars presenting indications for restoration due to the presence of caries lesions, or the necessity of replacing inadequate restorations. Class II compound supragingival cavities were included with marginal ridge involvement, including the mesialocclusal (MO) or distal-occlusal (DO) surface with a width of less than $1 / 3$ of the intercuspal distance. Patients, who had adjacent teeth available for contact with the surrounding tooth structure were selected.

All restorations were carried out by a single, experienced operator (10 years in the profession) using the three types of mold. The operator did not take part in the following evaluation steps.

The patients were selected and randomly divided into three experimental groups ( $\mathrm{n}=10$ each) to receive restorations using different matrix systems: group 1: Tofllemire carrier matrix type (Jon, Porto Alegre, RS, Brazil), coupled with metallic matrix and interproximal wood wedges (TDV, Curitiba, PR, Brazil) (G1-MMW); group 2: unimatrix sectioned metal matrix (TDV, Curitiba, $\mathrm{PR}$, Brazil), with retaining ring (Pomerode, SC, Brazil) and elastic interproximal wedges (TDV, Pomerode, SC, Brazil) (G2-SME); and group 3: unimatrix self-regulating polyester matrix (TVD, Curitiba, PR, Brazil) and reflective wedges (TDV, Curitiba, PR, Brazil) (G3-PMR). The polyester matrix utilized was self-regulating and preformed, and had a fitting that allowed it to be adjusted to the size of the tooth without the need for a carrier matrix.

The restorations were performed using a charisma microhybrid composite resin (Heraeus Kulzer, Pacaembu, SP, Brazil). Enamel etching was performed using 37\% phosphoric acid applied to the enamel for 30 seconds and to the dentin for 15 seconds, followed by thorough washing and indirect drying to avoid collapsing the collagen fibers. The Adper ${ }^{\mathrm{TM}}$ Single Bond 2 (3M/ESPE, St Paul, MN, USA) adhesive system was applied according to the manufacturer's guidelines. The insertion of the composite resin was performed using the incremental technique. Photopolymerization was performed using a polymerizing apparatus (Ultraled-Dabi Atlante, $\mathrm{SP}$, Brazil), with a light intensity of $500 \mathrm{~mW} / \mathrm{cm}^{2}$, in accordance with the manufacturer's guidelines.

After the restorative procedure, bitewing radiographs were taken to evaluate the proximal contour and contact point established at the end of the restoration. Thirty class II resin composite restorations on premolars were analyzed.

To standardize the exam radiographs, positioners were used (cone indicator-Indusbello, Londrina, PR, Brazil) with X-ray film (Kodak Insight, Rochester, USA). The radiographs were taken using an $\mathrm{X}$-ray machine 
(Gnatus, Ribeirão Preto, SP, Brazil) operating at $70 \mathrm{kVp}$ and $10 \mathrm{~mA}$, with an exposure time of 0.3 seconds. The radiographs were processed using the time/ temperature method.

Prior to the radiographic evaluation, the examiners were calibrated through the evaluation of 10 radiographs not included in the study. During this phase, the examiners became familiar with the evaluation method and scoring. Intraobserver statistical analysis was conducted using the Kappa coefficient, which revealed agreement of 0.83 between raters $A$ and $B, 0.96$ between $A$ and $C$, and 0.84 between $B$ and $C$.

Three calibrated dentists evaluated the radiographic images in isolation, resulting in a blind analysis of the studied groups. The proximal contour area and contact point were classified as correct or incorrect (Table 1). The proximal contour classification that appeared most frequently among the three evaluations was adopted. When none of the evaluations coincided, the three evaluators reexamined the radiographs, and a consensus score was adopted.

\section{STATISTICAL ANALYSIS}

The data were grouped in microsoft excel 2010 for windows spreadsheets (Microsoft Corporation ${ }^{\circledR}$, USA) and then subjected to statistical analysis.

Statistical analysis was performed using SPSS 18.0 software (SPSS, Inc, Chicago, IL, USA). To verify the existence of a statistically significant difference between the frequencies of restorations evaluated as correct in the different groups, Pearson's Chi-square test for independence was used. The significance level adopted was 5\%.

Table 1: Classification of proximal contour

\begin{tabular}{|c|c|c|}
\hline \multicolumn{3}{|c|}{ Classification } \\
\hline Correct & $\begin{array}{l}\text { Presence of tic } \\
\text { marginal adap }\end{array}$ & $\begin{array}{l}\text { ht proximal contact and proper } \\
\text { ation }\end{array}$ \\
\hline \multirow[t]{2}{*}{ Incorrect } & Undercontour & $\begin{array}{l}\text { No tight proximal contact and/ } \\
\text { or presence of undercontour in } \\
\text { the region corresponding to the } \\
\text { gingival wall }\end{array}$ \\
\hline & Overcontour & $\begin{array}{l}\text { Presence of tight proximal } \\
\text { contact and overcontour in the } \\
\text { region corresponding to the } \\
\text { gingival wall }\end{array}$ \\
\hline
\end{tabular}

Table 2: Frequency of restorations evaluated as correct and incorrect in the different groups $n(\%)\left(\alpha^{2}=6.787, p<0.05\right)$

\begin{tabular}{|c|c|c|c|}
\hline & \multicolumn{2}{|c|}{ Evaluation } & \multirow[b]{2}{*}{ Total (\%) } \\
\hline & Correct (\%) & Incorrect (\%) & \\
\hline G1 (MMW) & $4(40.0)$ & $6(60.0)$ & $10(100.0)$ \\
\hline G2 (SME) & $9(90.0)$ & $1(10.0)$ & $10(100.0)$ \\
\hline G3 (PMR) & $4(40.0)$ & $6(60.0)$ & $10(100.0)$ \\
\hline Total & $17(56.7)$ & $13(43.3)$ & $30(100.0)$ \\
\hline
\end{tabular}

\section{RESULTS}

In total, $56 \%$ of the patients evaluated were females, and $44 \%$ were males. The overall mean and standard deviation of the patients' age was $34.16 \pm 8.8$ years, and when evaluated according to gender, the mean ages and standard deviations were $36.46 \pm 8.5$ years for males and $32.41 \pm 8.5$ years for females.

In total, 17 (57\%) of the 30 restorations were evaluated as correct, with G2-SME achieving the highest frequency of correct evaluations; whereas in the other groups, the proportion was $40 \%$ correct and $60 \%$ incorrect (Table 2 ). Among the restorations classified as incorrect, 9 (69.20\%) of the 13 were considered as undercontour. Applying the Pearson Chi-square test, a statistically significant difference could be observed between the frequencies of restorations, evaluated as correct in the different groups $\left(\alpha^{2}=6.787, \mathrm{p}<0.05\right)$.

The proportion of restorations classified as incorrect was $56.2 \%$ for the 2 nd premolars and $28.6 \%$ for the 1 st premolars, although a statistically significant difference was not observed between the analyzed teeth $\left(\alpha^{2}=2.330\right.$; $\mathrm{p}=0.127$ ) (Table 3).

Regarding the evaluated surfaces, MO surfaces corresponded to $47.1 \%$ of the incorrect evaluations, and DO surfaces corresponded to only $38.5 \%$ of the incorrect evaluations. This difference in proportion was not statistically significant $\left(\alpha^{2}=0.222, \mathrm{p}=0.638\right)$ (Table 4$)$.

\section{DISCUSSION}

Tight proximal contact and a proper marginal adaptation play an important role in maintaining the integrity of the dental arch and in periodontal health. The null hypothesis for this study was rejected because there was a significant difference between the matrix system types used to perform class II proximal restorations with composite resin (Table 2).

Table 3: Proportion of evaluations classified as correct and incorrect according to the position of the tooth in the arches $\mathrm{n}(\%)$ $\left(\alpha^{2}=2.330 ; p>0.05\right)$

\begin{tabular}{lllll}
\hline & & \multicolumn{2}{c}{ Evaluation } & \\
\cline { 3 - 4 } & & Correct (\%) & Incorrect (\%) & Total (\%) \\
\hline \multirow{2}{*}{ Tooth } & 1st premolars & $10(71.4)$ & $4(28.6)$ & $14(100)$ \\
& 2nd premolars & $7(43.8)$ & $9(56.2)$ & $16(100)$ \\
\hline Total & & $17(56.7)$ & $13(43.3)$ & $30(100)$ \\
\hline
\end{tabular}

Table 4: Proportion of evaluations classified as correct and incorrect according to the treated surface $n(\%)\left(\alpha^{2}=0.222 ; p>0.05\right)$

\begin{tabular}{|c|c|c|c|c|}
\hline & & \multicolumn{2}{|c|}{ Evaluation } & \multirow[b]{2}{*}{ Total (\%) } \\
\hline & & $\begin{array}{l}\text { Correct } \\
\text { (\%) }\end{array}$ & $\begin{array}{l}\text { Incorrect } \\
(\%)\end{array}$ & \\
\hline \multirow{2}{*}{ Surface } & DO & $8(61.5)$ & $5(38.5)$ & $13(100.0)$ \\
\hline & MO & $9(52.9)$ & $8(47.1)$ & $17(100.0)$ \\
\hline Total & & $17(56.7)$ & $13(43.3)$ & $30(100.0)$ \\
\hline
\end{tabular}


After verifying the radiographic images, both undercontours and overcontours were observed among the proximal restorations, classified as incorrect. Undercontour and overcontour restorations cause damage to the dental element and the surrounding structures. A lack of tight proximal contact has been reported to be related to food impaction, and therefore to periodontal pocket depth. ${ }^{10}$ However, overcontour restorations also affect periodontal pocket depth. ${ }^{11}$ The effect of overcontour on periodontal pocket depth can have a synergic action, as deficient oral hygiene can cause this effect. Correct finishing and polishing of the gingival margins is essential in minimizing the build-up of bacterial plaque after performing restorations, because a large number of restorations present retentive areas. ${ }^{10}$

Regarding the gender and age distribution of the sample, $56 \%$ of the patients in this study were female, and $44 \%$ were male, with a mean age of $34.16 \pm 8.8$. It is reported that periodontal attachment loss due to caries or inadequate restoration is more likely to affect adults between the $3 \mathrm{rd}$ and 4 th decades of life. ${ }^{17}$ The association of caries or inadequate restoration represents a risk factor for periodontal attachment loss, and is aggravated by smoking.

None of the matrix devices used in the study was able to prevent the occurrence of incorrect proximal contours, corroborating studies found in the literature. ${ }^{5,9}$

In evaluating 3D images, it can be observed that interproximal matrix systems have some shortcomings in the reproduction of both contact tightness and contour. ${ }^{5}$ Kampouropoulos et al also observed significant differences between different matrix systems, noting that none of the devices used led to a reconstruction of tight proximal contact similar to that observed in healthy teeth. ${ }^{9}$

The results of this study indicate that the G2-SME presented the highest rate of correct proximal contour restorations. Likewise, in vitro studies corroborate these findings and demonstrate that for proximal contacts in class II restorations, composite resin separation with rings and the use of sectional matrices produce the best results. ${ }^{7,18,19}$ The results are also significantly better when precontoured and sectioned matrices with rings are used instead of circumferential matrix systems, coupled with a carrier matrix. ${ }^{5,20}$ The $3 \mathrm{D}$ analysis reveals that a sectioned and precontoured matrix generates significantly larger and deeper concavities, allowing the formation of an anatomical profile with concavity in the center of proximal surface, while a circumferential matrix generates flatter proximal profiles. ${ }^{5}$

The type of metal matrix retaining ring may also affect the final result of the restoration. In assessing the different types of rings or insertion techniques, none of the devices and techniques was able to completely prevent marginal overcontour; however, the type of resin insertion technique employed does have an effect on the occurrence of overcontour. ${ }^{6}$

Regarding the positioning of the tooth in the arch, no significant difference was observed between restorations on the 1st or 2nd premolars. In addition, no statistically significant difference was observed in the proportion of correct and incorrect restorations with regard to the treated surface (MO or $\mathrm{DO})$, in accordance with the findings from the literature. ${ }^{20}$

The results obtained demonstrate that there was no significant difference between G1-MMW and G3-PMR. Likewise, Prakki et al observed, after 18 months, no change in restorations performed using a metal and polyester strip. ${ }^{21}$ These devices resulted in satisfactory proximal contacts after preparation using incremental restorative techniques and insertion of pre-polymerized resin particulate. Using both metallic matrices with wood wedges and transparent matrices with reflective wedges, it was observed that all restorations exhibited overcontour, but no differences were found between the types of resins used..$^{22}$ The type of matrix used had a greater effect on the formation of the overcontour with metallic matrices, exhibiting significantly less excess material than when polyester straps with reflective wedges were used. ${ }^{22}$

Further in vivo studies are required to establish the clinical behavior of matrix systems associated with composite resin restorations in posterior teeth.

\section{CONCLUSION}

From the results obtained, the following conclusion were reached:

- No matrix systems were able to prevent resin overcontour in class II resin composite restorations.

- The matrix system type affects the efficiency of the proximal contour, and the G2-SME resulted in a higher incidence of correct proximal anatomical contours when compared with G1-MMW and G3PMR.

- The location of the restoration (mesial or distal) had no statistically significant effect on whether the proximal contacts were incorrect.

\section{REFERENCES}

1. Leinfelder KF, Radz GM, Nash RW. A report on a new condensable composite resin. Compend Contin Educ Dent 1998;19(3):230-232.

2. Lynch CD, Frazier KB, McConnell RJ, Blum IR, Wilson NH. State-of-the-art techniques in operative dentistry: contemporary teaching of posterior composites in UK and Irish dental schools. Br Dent J 2010;209(3):129-136. 
3. Lynch CD, McConnell RJ, Wilson NH. Teaching of posterior composite resin restorations in undergraduate dental schools in Ireland and the United Kingdom. Eur J Dent Educ 2006; 10(1):38-43.

4. Roeters FJ, Opdam NJ, Loomans BA. The amalgam-free dental school. J Dent 2004;32(5):371-377.

5. Chuang SF, Su KC, Wang $\mathrm{CH}$, Chang $\mathrm{CH}$. Morphological analysis of proximal contacts in class II direct restorations with 3D image reconstruction. J Dent 2011;39(6):448-456.

6. Loomans BA, Opdam NJ, Roeters FJ, Huysmans MC. Proximal marginal overhang of composite restorations in relation to placement technique of separation rings. Oper Dent 2012; 37(1):21-27.

7. Saber MH, El-Badrawy W, Loomans BA, Ahmed DR, Dorfer CE, El Zohairy A. Creating tight proximal contacts for MOD resin composite restorations. Oper Dent 2011;36(3): 304-310.

8. Wolff D, Hahn P, Ding P, Maier-Kraus T, Frese C, Doerfer C, Staehle HJ. Proximal contact tightness between directcomposite additions in the posterior dentition: an in vitro investigation. Oper Dent 2012;37(3):272-280.

9. Kampouropoulos D, Paximada C, Loukidis M, Kakaboura A. The influence of matrix type on the proximal contact in class II resin composite restorations. Oper Dent 2010;35(4):454-462.

10. Hancock EB, Mayo CV, Schwab RR, Wirthlin MR. Influence of interdental contacts on periodontal status. J Periodontol 1980;51(8):445-449.

11. Jansson L, Ehnevid H, Lindskog S, Blomlof L. Proximal restorations and periodontal status. J Clin Periodontol 1994; 21(9):577-582.

12. Oh SH, Nakano M, Bando E, Shigemoto S, Kori M. Evaluation of proximal tooth contact tightness at rest and during clenching. J Oral Rehabil 2004;31(6):538-545.
13. Hardan LS, Amm EW, Ghayad A, Ghosn C, Khraisat A. Effect of different modes of light curing and resin composites on microleakage of class II restorations-part II. Odontostomatol Trop 2009;32(126):29-37.

14. Lowe RA. The use of sectional matrix systems in class II direct composite restorations. Dent Today 2004;23(10):108-110.

15. Loomans BA, Opdam NJ, Roeters FJ, Bronkhorst EM, Burgersdijk RC. Comparison of proximal contacts of class II resin composite restorations in vitro. Oper Dent 2006;31(6): 688-693.

16. Peumans M, Van Meerbeek B, Asscherickx K, Simon S, Abe Y, Lambrechts P, Vanherle G. Do condensable composites help to achieve better proximal contacts? Dent Mater 2001;17(6): 533-541.

17. Broadbent JM, Williams KB, Thomson WM, Williams SM. Dental restorations: a risk factor for periodontal attachment loss? J Clin Periodontol 2006;33(11):803-810.

18. Raghu R, Srinivasan R. Optimizing tooth form with direct posterior composite restorations. J Conserv Dent 2011;14(4): 330-336.

19. Saber MH, Loomans BA, El Zohairy A, Dorfer CE, El-Badrawy W. Evaluation of proximal contact tightness of class II resin composite restorations. Oper Dent 2010;35(1):37-43.

20. Wirsching E, Loomans BA, Klaiber B, Dorfer CE. Influence of matrix systems on proximal contact tightness of 2- and 3 -surface posterior composite restorations in vivo. J Dent 2011;39(5):386-390.

21. Prakki A, Cilli R, Saad JO, Rodrigues JR. Clinical evaluation of proximal contacts of class II esthetic direct restorations. Quintessence Int 2004;35(10):785-789.

22. Mullejans R, Badawi MO, Raab WH, Lang H. An in vitro comparison of metal and transparent matrices used for bonded class II resin composite restorations. Oper Dent 2003; 28(2):122-126. 